Brit. Heart J., 1965, 27, 902.

\title{
EFFECT OF NITROGLYCERIN ON CARDIOVASCULAR FUNCTION AT FIXED AND AT VARIABLE HEART RATE*
}

\author{
BY
ALBERTO BENCHIMOL, MARVIN S. LIGGETT, AZARIA DUENAS, AND E. GREY DIMOND \\ From the Institute for Cardiopulmonary Diseases, Scripps Clinic and Research Foundation, \\ La Jolla, California, U.S.A. \\ Received February 22, 1965
}

This work was undertaken in order to study the effect of nitroglycerin on (a) the cardiac functions in patients with a fixed ventricular rate due to complete heart block and in patients with normal sinus rhythm, and (b) the contribution of atrial systole to ventricular filling at a fixed ventricular rate.

\section{SubJects AND MeTHODS}

Studies were carried out on 23 patients divided into 2 groups:

Group 1. 14 consecutive patients with complete heart block were studied, whose ages ranged from 55 to 76 with a group average of $70 \cdot 2$ years. Aetiology of the heart block in 8 patients was considered to be coronary artery disease, as judged by clinical and laboratory evidence. In 6, all of whom developed block past age 50, no probable ætiology could be assigned. Of the 14 patients, 8 had the wires of a fixed rate permanent pacemaker (Chardack-Greatbatch) implanted in the free wall of the left ventricle; in the remaining 6 the heart was stimulated by means of a bipolar electrode catheter placed in the right ventricle and connected to an external pacemaker (Model TR-3).

Group 2. 9 patients with normal sinus rhythm were studied: 4 had coronary disease, 1 had essential hypertension, and 4 had no evidence of heart disease. Their ages ranged from 45 to 72 years with a group average of 60 years.

Cardiac output was determined with the indicator-dilution technique using indocyanine as an indicator. Details of this technique were described in a previous report (Benchimol et al., 1963). The indicator was rapidly injected into the left cubital vein with sampling from the brachial artery through a No. 18 Cournand needle. A Gilford cuvette densitometer§ (Model 103 IR) was used to detect the injected dye. The curves were recorded in the Electronics for Medicine oscilloscopic photographic recorder** (Model DR-8) at a paper speed of $5 \mathrm{~mm}$./sec. The cardiac output was calculated with the Stewart-Hamilton method in 14 patients. In the remaining 9 the output of the densitometer was coupled with a dye-dilution

Note: Tables giving the full clinical details and results of hæmodynamic studies have been prepared by the authors. They are not published here, but workers wishing for such information should apply directly to Dr. Alberto Benchimol at Scripps Clinic and Research Foundation, 476 Prospect Street, La Jolla, California, U.S.A.

* Supported in part by NIH Research Grant HE-07983-02, NIH Graduate Training Grant HE-5513-03, and by the Timken-Sturgis Foundation.

$\dagger$ Electrodyne Company, Norwood, Massachusetts.

$\ddagger$ Hynson, Westcott and Dunning, Inc., Baltimore, Maryland.

§ Gilford Instruments, Oberlin, Ohio.

** Electronics for Medicine, White Plains, New York. 
computer* (Model 130), and the cardiac output derived from the area calculated by the computer (Benchimol, Akre, and Dimond, 1965a).

The pacemaker rate was fixed at a range of the "optimum rate" of pacing as defined in our previous studies (Benchimol, Li, and Dimond, 1964a; Benchimol, Wu, and Liggett, 1965b), which was between 60 and 80 impulses per minute with an average for the group of 73 beats $/ \mathrm{min}$. Three to five determinations of all parameters were obtained, averaged, and designated as control. The patients were then given one tablet of $0.4 \mathrm{mg}$. of nitroglycerin sublingually and the parameters measured at $1,2,4,6,10,15,20$, and 30 minutes after the administration of the drug.

The ventricular rate was measured using lead II of the electrocardiogram simultaneously recorded with the dye-dilution computer.

Arterial pressures were recorded with a P23Db Statham transducer. Mean pressures were obtained by electronic filtering. The rate of change in the brachial artery pressure, i.e. $\mathrm{dp} / \mathrm{dt}$, was obtained in 3 patients by means of an R-C differentiating circuit. Peripheral resistance, average ventricular power, and stroke power were calculated from previously described formulæ (Gorlin et al., 1951). Peak systolic pressure was used in Sarnoff's formula for calculation of the tension-time index (Sarnoff et al., 1958a). Ejection time was derived from the indirect carotid tracing recorded at a paper speed of $200 \mathrm{~mm}$./ $/ \mathrm{sec}$. with $20 \mathrm{msec}$. time lines (Benchimol, Dimond, and Shen, 1960). The ejection time was corrected for the heart rate in the group with variable ventricular rate, according to Weissler's formula (Weissler et al., 1964). Mechanical systole was calculated from a medium frequency (40 to 200 cycles/second) phonocardiogram recorded at the mitral area, using a high impedance Cambridge crystal microphone in held expiration. Mechanical systole minus ejection time was taken as isometric contraction time.

Ejection time, mechanical systole, isometric contraction time, arterial pressures, peak derivative of arterial pressure, tension-time index, and mean systolic ejection rate were analysed as functions of the P-R interval (Benchimol et al., 1965c) before and after nitroglycerin as follows: (a) P occurring during ventricular systole (PS); (b) P-R interval from 1 to $300 \mathrm{msec}$; (c) P-R interval from 301 to 500 msec. The values obtained for $\mathbf{P}$ waves occurring during ventricular systole were taken as the control figures. The data were analysed statistically and the $p$ values obtained for the differences.

\section{RESULTS}

Group 1. Fourteen patients with complete heart block and with a fixed ventricular rate were studied.

Cardiac Index: The cardiac index did not change significantly after the administration of nitroglycerin. The average control figure was $2.571 . / \mathrm{min} . / \mathrm{m}^{2}$ as compared with $2.521 . / \mathrm{min} . / \mathrm{m}^{2}{ }^{2}$ obtained during the fourth minute after the administration of nitroglycerin (Fig. 1 and 2). The mean of the difference was $0.008 \pm 0 \cdot 11 . / \mathrm{min} . / \mathrm{m} .^{2}(\mathrm{p}<0.05) \dagger$.

Stroke Index: Since the heart rate was fixed the changes in the stroke index paralleled the ones obtained for the cardiac index (Fig. 1 and 2).

Central Blood Volume Index: This parameter was measured in 7 patients. Nitroglycerin induced a decrease in this parameter in 3 patients. In the remaining 4 no significant changes were observed. The average central blood volume index in the control figures was $0.911 . / \mathrm{m} .{ }^{2}$ as compared with $0.761 . / \mathrm{m}^{2}$ obtained 4 minutes after the administration of the drug (Fig. 3).

Mean Circulation Time: This parameter was measured in 7 patients. The changes observed after the administration of the drug were not significant. The average mean circulation time for the control figure was $21 \mathrm{sec}$. as compared with $19 \mathrm{sec}$. recorded 4 minutes after the administration of the drug (Fig. 4).

Mean Brachial Artery Pressure: The average mean brachial artery pressure decreased from a control of $105 \mathrm{~mm}$. Hg to $70 \mathrm{~mm}$. $\mathrm{Hg} \mathrm{(34 \%} \mathrm{decrease)} \mathrm{observed} 6$ minutes after the administration of nitroglycerin. The mean of the difference was $15 \pm 2 \mathrm{~mm}$. $\mathrm{Hg}(\mathrm{p}<0.05)$ (Fig. 3).

Peripheral Resistance: The average peripheral resistance was 1709 dynes sec./cm. ${ }^{5}$ and fell to 1458 dynes sec. $/ \mathrm{cm}^{5}$ ( $15 \%$ decrease) when measured 4 minutes after the administration of the drug.

* Sanborn Company, Waltham, Massachusetts.

$\dagger$ The numbers appearing to the right of the \pm sign represent one standard deviation of the mean difference. $3 \mathrm{~L}$ 


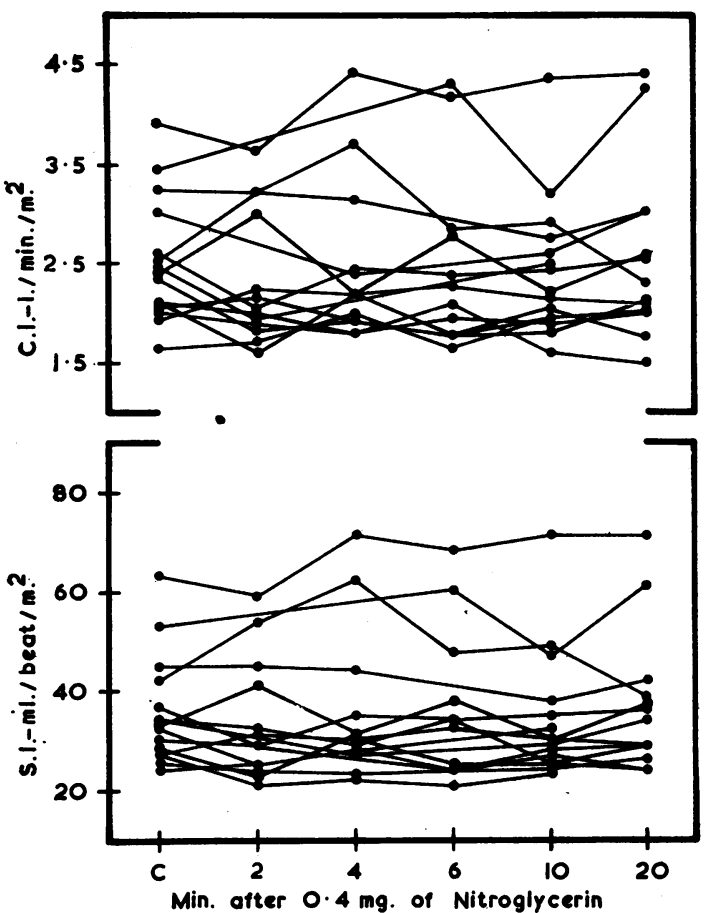

FIG. 1.-Cardiac index (C.I.) and stroke index (S.I.) in patients with complete heart block before and after sublingual administration of $0.4 \mathrm{mg}$. of nitroglycerin.

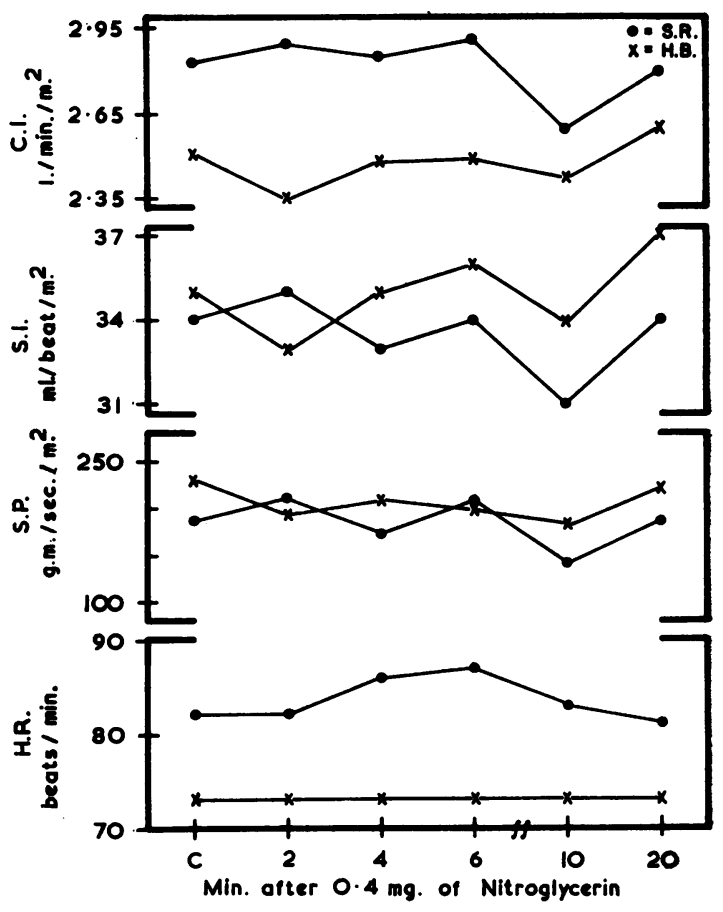

FIG. 2.-Average cardiac index (C.I.), stroke index (S.I.) stroke power (S.P.), and heart rate (H.R.) in the groups with fixed and variable heart rate. H.B. $=$ heart block (Group I). S.R.=sinus rhythm (Group 2).

The mean of the difference was $315 \pm 70$ dynes sec. $/ \mathrm{cm} . .^{5}(\mathrm{p}>0.001)$. These changes began within one minute after the administration of nitroglycerin and persisted for as long as 20 minutes (Fig. 3).

Average Ventricular Power: The average ventricular power obtained for the control figures was $4.7 \mathrm{~kg} . \mathrm{m} . / \mathrm{min} . / \mathrm{m}^{2}$ Administration of nitroglycerin resulted in a uniform decrease in this parameter with a maximum response obtained at 10 minutes when it averaged $3.7 \mathrm{~kg} . \mathrm{m} . / \mathrm{min} . / \mathrm{m} .{ }^{2}$ $\left(21 \%\right.$ decrease). The mean of the difference was $1.01 \pm 0.18 \mathrm{~kg} . \mathrm{m} . / \mathrm{min} . / \mathrm{m} .{ }^{2}$ (p $\left.>0.001\right)$ (Fig. 3 ).

Stroke Power: The average control stroke power was $232 \mathrm{~g} . \mathrm{m} . / \mathrm{sec} . / \mathrm{m} .^{2}$ and it decreased to $202 \mathrm{~g}$. $\mathrm{m} . / \mathrm{sec} . / \mathrm{m} .{ }^{2}$ after nitroglycerin $\left(13 \%\right.$ decrease). The mean of the difference was $42 \pm 7 \mathrm{~g} . \mathrm{m} . / \mathrm{sec} . / \mathrm{m} .{ }^{2}$ $(\mathrm{p}>0.001)$ (Fig. 2).

Influence of Atrial Systole on Cardiac Functions Before and After Administration of Nitroglycerin. Ventricular Rate: The ventricular rate was fixed throughout the study in all patients. The rate of artificial pacing ranged from 60 to 86 beats $/ \mathrm{min}$. with an average of 73 beats $/ \mathrm{min}$. The administration of nitroglycerin did not produce changes in the ventricular rate.

Ejection Time: Variations in the ejection time occurred in the control figures as a function of the $\mathbf{P}-\mathbf{R}$ interval. When atrial systole occurred during ventricular systole the ejection time was 276 msec. as compared with $293 \mathrm{msec}$. for the $P-R$ interval of 1 to $300 \mathrm{msec}$. With an increase in the $\mathrm{P}-\mathrm{R}$ interval to a range of 301 to $500 \mathrm{msec}$. the ejection time decreased to $275 \mathrm{msec}$. Nitroglycerin resulted in a progressive decrease in the ejection time for all ranges of the $P-R$ interval (Fig. 5 and 6) with a mean difference before and after nitroglycerin of $31 \pm 6 \mathrm{msec} .(\mathrm{p}>0.001)$ for the $P-R$ interval of 1 to $300 \mathrm{msec}$. When atrial systole occurred during ventricular systole the mean difference before and after nitroglycerin was $26 \pm 6 \mathrm{msec}$. ( $\mathrm{p}>0.001)$.

Brachial Artery Pressure: As described previously (Benchimol et al., 1964a), beat-to-beat 


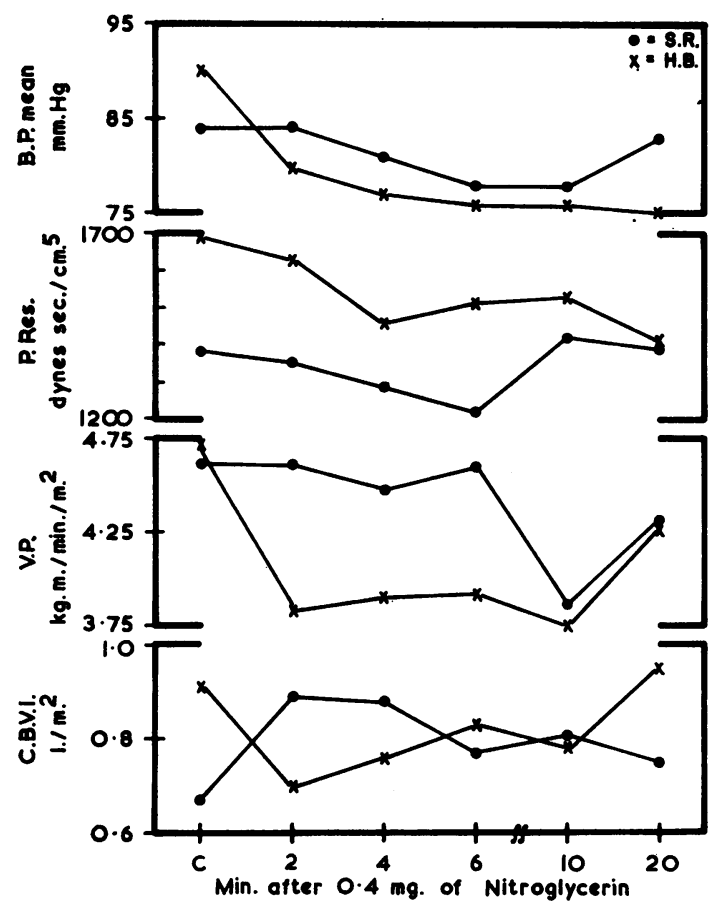

Fig. 3.-Average brachial artery mean pressure (B.P. mean), peripheral resistance (P. Res.), average ventricular power (V.P.), and central blood volume index (C.B.V.I.) in the groups with fixed and variable heart rate.

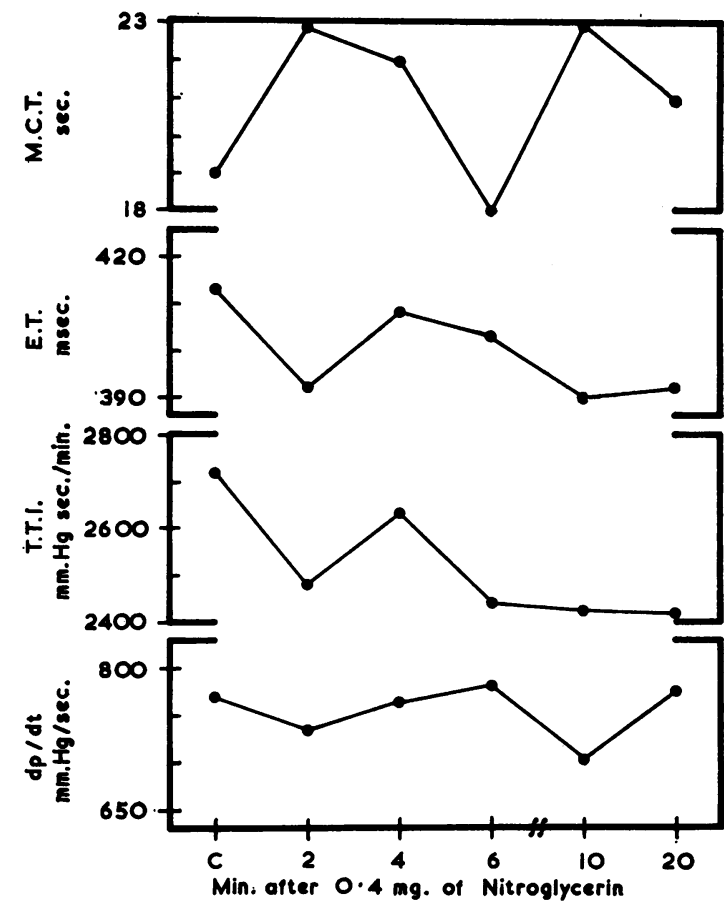

FIG. 4.-Average mean circulation time (M.C.T.), ejection time (E.T.), tension-time index (T.T.I.), and first derivative of brachial artery pressure $(\mathrm{dp} / \mathrm{dt})$ in the groups with fixed and variable heart rate.

variations in the systolic and diastolic pressures occurred in all patients as a function of the $\mathbf{P}-\mathbf{R}$ interval. The higher figures were obtained when atrial systole occurred in the range of 1 to $300 \mathrm{msec}$. from ventricular systole. Administration of nitroglycerin resulted in a uniform decrease in the systolic and diastolic pressures for any given range of the P-R interval (Fig. 5 and 6) with a mean difference of the systolic pressure before and after nitroglycerin of $34 \pm 8 \mathrm{~mm} . \mathrm{Hg}(\mathrm{p}>0.001)$ for the P-R interval of 1 to $300 \mathrm{msec}$. The mean difference of the diastolic pressure before and after nitroglycerin was $6 \pm 1 \mathrm{~mm} . \mathrm{Hg}(\mathrm{p}<0.05)$ for the $\mathrm{P}-\mathrm{R}$ interval of 1 to $300 \mathrm{msec}$.

$d p / d t$ : The first derivative of the brachial artery pressure showed variations in the control figures related to the $\mathbf{P}-\mathbf{R}$ interval. When atrial systole occurred during ventricular systole the $\mathrm{dp} / \mathrm{dt}$ was $708 \mathrm{~mm}$. Hg/sec. This parameter rose to $843 \mathrm{~mm} . \mathrm{Hg} / \mathrm{sec}$. (19\% increase) for the P-R interval of 301 to $500 \mathrm{msec}$. Nitroglycerin resulted in a progressive decrease in the dp/dt for all ranges of the P-R interval (Fig. 5 and 7). Ten minutes after the administration of the drug the dp/dt was $437 \mathrm{~mm}$. $\mathrm{Hg} / \mathrm{sec}$. (43\% decrease) for atrial systole occurring during ventricular systole, $549 \mathrm{~mm} . \mathrm{Hg} / \mathrm{sec} .(22 \%$ decrease) for the P-R interval of 1 to $300 \mathrm{msec}$., and $621 \mathrm{~mm}$. Hg/sec. (26\% decrease) for the P-R interval of 301 to $500 \mathrm{msec}$.

Tension-time Index: The tension-time index in the control figures averaged $2664 \mathrm{~mm} . \mathrm{Hg} \mathrm{sec} . /$ min. when atrial systole occurred during ventricular systole, $3143 \mathrm{~mm}$. $\mathrm{Hg} \mathrm{sec} . / \mathrm{min}$. for the P-R interval of 1 to $300 \mathrm{msec}$, and $2900 \mathrm{~mm}$. $\mathrm{Hg} \mathrm{sec}$. $/ \mathrm{min}$. for the P-R interval of 301 to $500 \mathrm{msec}$. Nitroglycerin resulted in a uniform decrease in the tension-time index $(30 \%$ for the PS, $31 \%$ for the P-R interval of 1 to $300 \mathrm{msec}$., and $28 \%$ for the P-R interval of 301 to $500 \mathrm{msec}$.). The mean of the 


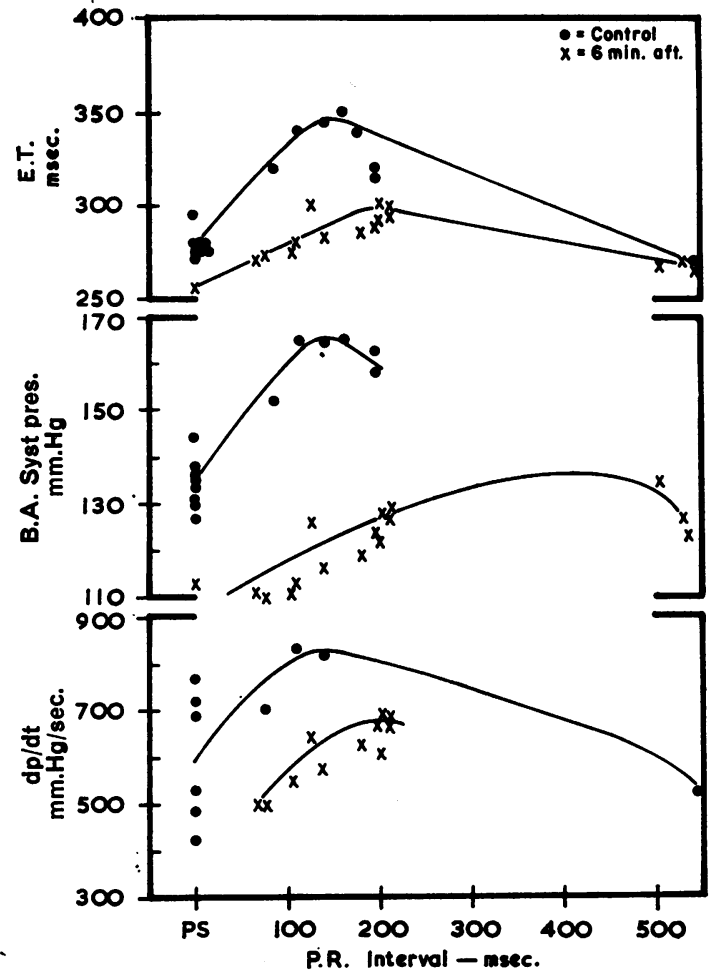

FIG. 5.-Ejection time (E.T.), brachial artery systolic pressure (B.A. Syst. pres.), and first derivative of brachial artery pressure (dp/dt) as a function of the $\mathbf{P}-\mathbf{R}$ interval in a patient with complete heart block before and after (6 minutes) nitroglycerin. $\mathbf{P S}=\mathbf{P}$ wave occurring during ventricular systole.

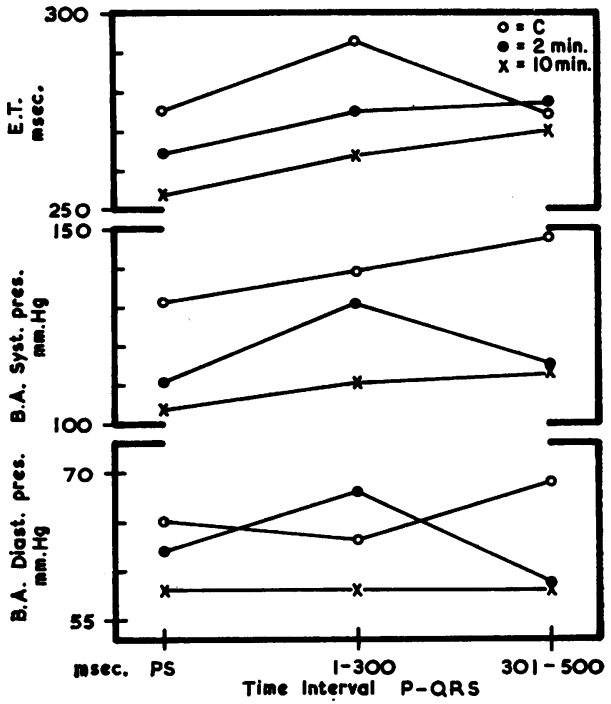

FIG. 6.-Average ejection time (E.T.), brachial artery systolic pressure (B.A. Syst. pres.), and brachial artery diastolic pressure (B.A. Diast. pres.) in the group with complete heart block before and 2 and 10 minutes after nitroglycerin. $\mathbf{P S}=\mathbf{P}$ wave occurring during ventricular systole.

difference before and after nitroglycerin for the PS was $844 \pm 164 \mathrm{~mm} . \mathrm{Hg} \mathrm{sec} . / \mathrm{min} .(\mathrm{p}>0.001)$, and $1153 \pm 237 \mathrm{~mm}$. Hg sec./min. ( $\mathrm{p}>0.001$ ) for the P-R interval of 1 to $300 \mathrm{msec}$. (Fig. 7).

Mean Systolic Ejection Rate: Nitroglycerin did not produce any significant changes in this parameter (Fig. 7).

Isometric Contraction Time: The isometric contraction time increased in the control figures from $64 \mathrm{msec}$. for the PS to $102 \mathrm{msec}$. for the P-R interval of 301 to $500 \mathrm{msec}$. Nitroglycerin decreased the isometric contraction time to $49 \mathrm{msec}$. (23\% decrease), $42 \mathrm{msec}$. (39\% decrease), and $57 \mathrm{msec}$. (17\% decrease) for PS, 1 to $300 \mathrm{msec}$. and 301 to $500 \mathrm{msec}$., respectively.

Group 2. Nine patients with normal sinus rhythm were studied. There was no significant difference within this group between patients with heart disease as compared with patients without heart disease. Therefore, this group will be discussed as a whole.

Cardiac Index: The cardiac index did not change significantly after the administration of nitroglycerin (Fig. 2). The control figure was $2 \cdot 841 . / \mathrm{min} . / \mathrm{m} .{ }^{2}$ as compared with $2.851 . / \mathrm{min} / \mathrm{m} .{ }^{2}$ four minutes after the administration of the drug. The mean difference before and after nitroglycerin was $0.05 \pm 0.141 . / \mathrm{min} . / \mathrm{m} .^{2}(\mathrm{p}<0.05)$.

Stroke Index: The stroke index did not change significantly after the administration of nitroglycerin, being $34 \mathrm{ml}$./beat $/ \mathrm{m}^{2}{ }^{2}$ in the control figure and $33 \mathrm{ml} . /$ beat $/ \mathrm{m} .{ }^{2}$ four minutes after the administration of the drug (Fig. 2).

Brachial Artery Pressure: There was a uniform mild decrease in the systolic arterial pressure after 
the administration of nitroglycerin which fell from an average of $123 \mathrm{~mm}$. $\mathrm{Hg}$ to $116 \mathrm{~mm}$. $\mathrm{Hg}$ $(6 \%$ decrease). The diastolic pressure did not change significantly. The mean arterial pressure fell from $84 \mathrm{~mm}$. $\mathrm{Hg}$ to $78 \mathrm{~mm}$. $\mathrm{Hg}(8 \%$ decrease). The mean difference before and after nitroglycerin was $6 \pm 4 \mathrm{~mm}$. $\mathrm{Hg}(\mathrm{p}<0.05)$, $2 \pm 2 \mathrm{~mm}$. $\mathrm{Hg}(\mathrm{p}<0.05)$, and $8 \pm 3 \mathrm{~mm}$. $\mathrm{Hg}$ $(\mathrm{p}<0.02)$, for the systolic, diastolic, and mean pressures, respectively (Fig. 3 and 6).

Peripheral Resistance: The peripheral resistance decreased from a control of 1384 dynes $\mathrm{sec} . / \mathrm{cm} .5$ to 1226 dynes sec. $/ \mathrm{cm} .{ }^{5}(11 \%$ decrease $)$ six minutes after the administration of nitroglycerin (Fig. 3). The mean difference before and after nitroglycerin was $103 \pm 60$ dynes sec. $/ \mathrm{cm} .{ }^{5}(\mathrm{p}<0.05)$.

Ejection Time: There was a tendency for a decrease in the ejection time which fell from a control average of $413 \mathrm{msec}$. to $390 \mathrm{msec}$. $(6 \%$ decrease) observed ten minutes after the administration of nitroglycerin (Fig. 6). The mean difference before and after nitroglycerin was $12 \pm 2$ msec. ( $p>0.001$ ).

Heart Rate: There was a variable response in the heart rate. The resting rate was 82 beats/

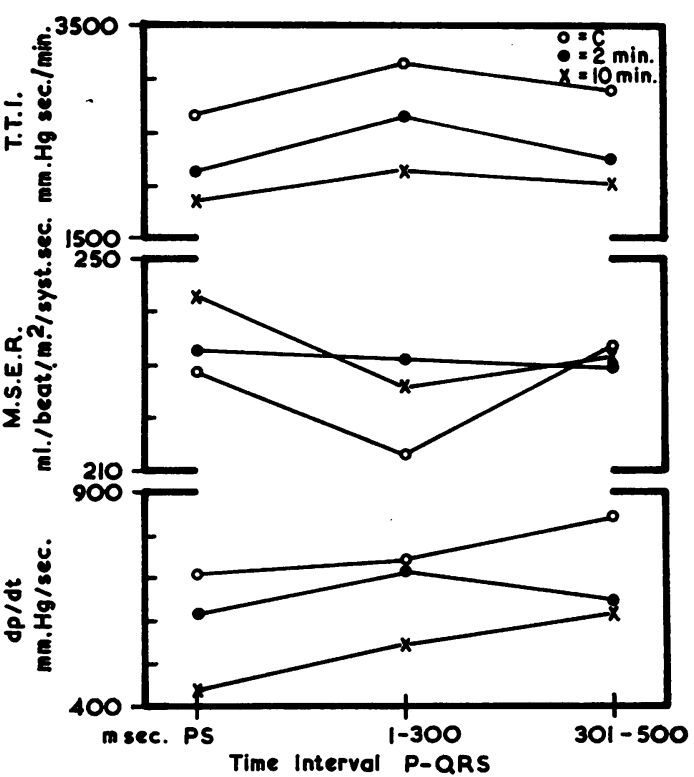

FIG. 7.-Average tension-time index (T.T.I.), mean systolic ejection rate (M.S.E.R.), and first derivative of brachial artery pressure (dp/dt) as a function of the $\mathbf{P}-\mathbf{R}$ interval in the group with complete heart block before and 2 and 10 minutes after nitroglycerin. $\mathbf{P S}=\mathbf{P}$ wave occurring during ventricular systole. min. as compared with 87 beats $/ \mathrm{min}$. $(6 \%$ in crease) obtained six minutes after the administration of the drug (Fig. 2). The mean difference before and after nitroglycerin was $4 \pm 2$ beats/min. $(p<0.05)$.

Tension-time Index: The tension-time index fell from a control of $2726 \mathrm{~mm}$. $\mathrm{Hg} \mathrm{sec} . / \mathrm{min}$. to $2428 \mathrm{~mm}$. Hg sec./min. (11\% decrease) 10 minutes after the administration of nitroglycerin (Fig. 4). The mean difference before and after nitroglycerin was $270 \pm 37 \mathrm{~mm}$. $\mathrm{Hg}$ sec. $/ \mathrm{min}$. (p>0.001).

Ventricular Power: The average ventricular power was $4.62 \mathrm{~kg} . \mathrm{m} . / \mathrm{min} . / \mathrm{m}^{2}$ and it fell to $3.86 \mathrm{~kg}$. $\mathrm{m} . / \mathrm{min} . / \mathrm{m} .{ }^{2}(17 \%$ decrease) 10 minutes after the administration of nitroglycerin (Fig. 3$)$. The mean difference before and after nitroglycerin was $0.30 \pm 0.3 \mathrm{~kg} . \mathrm{m} . / \mathrm{min} . / \mathrm{m} .{ }^{2}(\mathrm{p}<0.05)$.

Stroke Power: The average stroke power at rest was $188 \mathrm{~g} . \mathrm{m} . / \mathrm{sec} . / \mathrm{m} .{ }^{2}$ and decreased to $141 \mathrm{~g}$. $\mathrm{m} . / \mathrm{sec} . / \mathrm{m} .^{2}$ (25\% decrease) 10 minutes after the administration of nitroglycerin (Fig. 1).

$d p / d t$ : The first derivative of the brachial artery pressure fell from a control of $770 \mathrm{~mm} . \mathrm{Hg} / \mathrm{sec}$. (12\% decrease) obtained 6 minutes after the administration of nitroglycerin (Fig. 4).

\section{DisCUSSION}

Previous reports have indicated a variable effect of nitroglycerin on coronary flow, ventricular work, and myocardial efficiency in man and in experimental animals (Cameron, 1911; Katz et al., 1938; Essex et al., 1940; Wégria et al., 1951 ; Brandt, Caccese, and Dock, 1952; Eldridge et al., 1955; Müller and Rørvik, 1958; Sarnoff, Case, and Macruz, 1958b; Brachfeld, Bozer, and Gorlin, 1959; Gorlin et al., 1959; Russek, Urbach, and Zohman, 1955; Gregg, 1950; Case and Roven, 1963; Johnson, Fairley, and Carter, 1959; Honig, Tenney, and Gabel, 1960; Bergamaschi and Glässer, 1963). Discrepancies are due, in part, to the fact that this drug affects cardiovascular function in a rapid manner and, therefore, measurements of the various parameters need to be performed at very frequent intervals. Determination of blood flow and other values cannot be obtained adequately 
with techniques that require a prolonged steady state. With the introduction of the indicatordilution technique to measure cardiac output, the possibility of rapid determinations of the cardiac output in man became possible (Benchimol, $\mathrm{Li}$, and Dimond, 1964b). In this present study rapidly repeated measurements of the cardiac functions were obtained before and after the administration of sublingual nitroglycerin.

Our findings indicate that nitroglycerin does not significantly alter the cardiac output and stroke volume in patients with sinus rhythm nor in patients in whom the ventricular rate was maintained fixed with the use of a cardiac pacemaker.

Honig et al. (1960) found that in normal dogs cardiac output increased 10 to 55 per cent after the administration of nitroglycerin and that this effect was observed during the maximal decrease in the diastolic pressure. They concluded that nitroglycerin relieved ischæmia by enhancing oxygen delivery rather than by altering load. Our observations demonstrated that despite a significant decrease in the systemic pressure the cardiac output did not change significantly after the administration of the drug to either the group with the fixed or the variable heart rate. It is conceivable that the increase in the cardiac output reported by others may have resulted from an increase in heart rate. The lack of change in the cardiac output was also reported by Brachfeld et al. (1959) in patients without coronary disease and with a normal sinus rhythm.

Gorlin et al. (1959) showed a striking decrease in left ventricular work after nitroglycerin, and this was interpreted as the effect of nitroglycerin on circulatory functions via the myocardium as well as via the peripheral vessels.

Bing et al. (1949) postulated that nitroglycerin might exert its beneficial action in angina pectoris by relieving accompanying failure. In support of this view, Johnson et al. (1959) and Müller and Rørvik (1958) demonstrated that nitroglycerin decreased the raised left ventricular end-diastolic pressure found during anginal attack. We have also confirmed the fact that the left ventricular enddiastolic pressure is raised in patients with ischæmic heart disease, and that nitroglycerin decreases this pressure and prevents its rise during exercise (Fig. 8) (Benchimol and Dimond, 1963; Dimond and Benchimol, 1963).

Whether the raised end-diastolic pressure represents a form of left ventricular failure or a de-

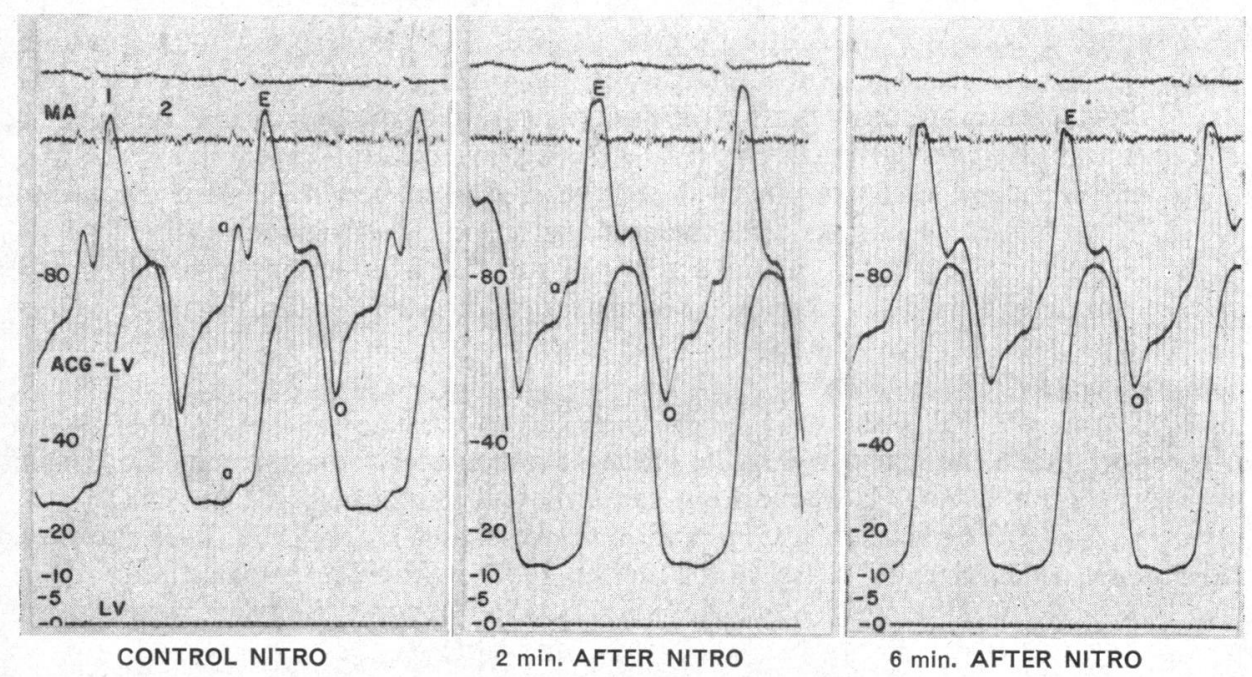

FIG. 8. Apex cardiogram (ACG), phonocardiogram at the mitral area (MA), and left ventricular pressure curve (ACG-LV) in a patient with ischæmic heart disease and sinus rhythm before and after the administration of $0.4 \mathrm{mg}$. of nitroglycerin. 
creased ventricular distensibility is not known at the present time. Bing et al. (1949) suggested that this drug might exert its effects by reduction of myocardial oxygen requirements and by a venous pooling effect.

Williams and Glick (1964) demonstrated recently that nitroglycerin reduced ventricular dimension in man free of coronary disease. In view of the relation between ventricular dimension and myocardial oxygen consumption, they concluded that this drug favourably influenced the balance between oxygen availability and oxygen requirements which could in part explain the beneficial effect of this drug in relieving angina pectoris. These observations appear to correlate well with the conclusions of Weiss and Ellis (1933) and Brandt et al. (1952) who demonstrated that nitroglycerin decreased heart volume and stroke volume in dogs. Sarnoff et al. (1958b) showed in isolated dog hearts with fixed work and heart rate that nitroglycerin acted as a "pure dilator" with decreased arteriovenous oxygen extraction as coronary flow increased.

In another study, Sarnoff et al. (1958a) demonstrated the primary determinant of myocardial oxygen utilization to be the total tension developed by the myocardium, which was termed the tension-time index. For a given increase in work, oxygen utilization was greater when this increment was induced by increasing pressure (cardiac output constant) than it was when the increment was induced by increasing cardiac output (pressure constant). Thus, one might conclude that "pressure costs more oxygen than flow".

Our data indicate that nitroglycerin induces a significant decrease in the average ventricular and stroke powers and peripheral resistance in patients with fixed ventricular rate in the absence of changes in the cardiac output. Therefore, these findings appear to support the theory that this drug produces its main cardiovascular effect on the peripheral circulation, and, in so doing, reduces work requirements of the myocardium. The reported increase in the coronary flow in the experimental animals and in humans appears to represent the result of coronary artery dilatation which is part of the general effect of the drug, but not necessarily the primary reason for its salutary effect.

In patients with heart block, nitroglycerin resulted in a progressive decrease in ejection time, brachial artery pressure, $\mathrm{dp} / \mathrm{dt}$, and tension-time index for any given range of the $\mathbf{P}-\mathbf{R}$ interval. However, the contribution of atrial systole to the increase in these parameters continues to be present and to the same extent as observed before administration of the drug.

\section{Summary AND CONClusions}

The cardiovascular effects of nitroglycerin were studied in 14 patients with complete heart block and fixed ventricular rate and in 9 patients with normal sinus mechanism.

In patients with complete heart block nitroglycerin did not change the cardiac index, stroke index, and mean circulation time. However, it induced a 34, 15, 21, and 13 per cent decrease in the mean brachial artery pressure, peripheral resistance, average ventricular power, and stroke power, respectively.

Analysis of beat-to-beat variation in relation to the P-R interval was made for the values of the ejection time, brachial artery pressure, tension-time index, first derivative of the brachial artery pressure, and mean systolic ejection rate before and after administration of nitroglycerin. When the $\mathbf{P}$ wave occurred during ventricular systole, nitroglycerin induced $8,24,43$, and 26 per cent decreases in ejection time, brachial artery systolic pressure, first derivative of the brachial artery pressure, and tension-time index, respectively. It did not significantly change the values for the mean systolic ejection rate and isometric contraction time.

Nitroglycerin also resulted in 5, 14, 22, and 20 per cent decreases in ejection time, brachial artery systolic pressure, first derivative of the brachial artery pressure, and tension-time index, respectively, for the P-R interval of 1 to 300 msec.

In patients with sinus mechanism nitroglycerin induced $8,6,11,17,25,12$, and 11 per cent decreases in the mean arterial pressure, ejection time, tension-time index, ventricular power, stroke power, $\mathrm{dp} / \mathrm{dt}$, and peripheral resistance, respectively. Cardiac index and stroke index did not change significantly. The heart rate increased by only 6 per cent. 
We wish to thank Mrs. Mary Vensel, Miss Marilyn Hanna, Miss Shirley Cardwell, and Miss Ann Wall for their technical assistance.

\section{REFERENCES}

Benchimol, A., Akre, P. R., and Dimond, E. G. (1965a). Clinical experience with the use of computers for calculation of cardiac output. Amer. J. Cardiol., 15, 213.

- and Dimond, E. G. (1963). The apexcardiogram in normal older subjects and in patients with arteriosclerotic heart disease. Effect of exercise on the "a" wave. Amer. Heart J., 65, 789.

,-- and Shen, Y. (1960). Ejection time in aortic stenosis and mitral stenosis. Comparison between the direct and indirect arterial tracings, with special reference to pre- and post-operative findings. Amer. J. Cardiol., $\mathbf{5}, 728$.

, Duenas, A., Liggett, M. S., and Dimond, E. G. (1965c). Contribution of atrial systole to the cardiac function at a fixed and at a variable ventricular rate. Amer. J. Cardiol., 16, 11.

, Li, Y. B., and Dimond, E. G. (1964a). Cardiovascular dynamics in complete heart block at various heart rates. Effect of exercise at a fixed heart rate. Circulation, $30,542$.

, and - $(1964 \mathrm{~b})$. Rapidly repeated determinations of the cardiac output with the indicator-dilution technic. Amer. J. Cardiol., 13, 790.

,--1, Voth, R. B., and Roland, A. S. (1963). Effect of heart rate, exercise, and nitroglycerin on the cardiac dynamics in complete heart block. Circulation, 28, 510.

- Wu, T. L., and Liggett, M. S. (1965b). Effect of exercise and isoproterenol on the cardiovascular dynamics in complete heart block at various fixed heart rates. Amer. Heart $J$. In the press.

Bergamaschi, M., and Glässer, A. H. (1963). Effect of the endecapeptide Eledoisin on the coronary blood flow: Comparison with nitroglycerin, bradykinin and epinephrine in the dog. Circulat. Res., 13, 329.

Bing, R. J., Hammond, M. M., Handelsman, J. C., Powers, S. R., Spencer, F. C., Eckenhoff, J. E., Goodale, W. T., Hafkenschiel, J. H., and Kety, S. S. (1949). The measurement of coronary blood flow, oxygen consumption, and efficiency of the left ventricle in man. Amer. Heart J., 38, 1.

Brachfeld, N., Bozer, J., and Gorlin, R. (1959). Action of nitroglycerin on the coronary circulation in normal and in mild cardiac subjects. Circulation, 19, 697.

Brandt, J. L., Caccese, A., and Dock, W. (1952). Slit-kymographic evidence that nitroglycerine decreases heart volume and stroke volume. Amer. J. Med., 12, 650.

Cameron, P. D. (1911). Physiological and pharmacological studies on cardiac tonicity in mammals. Johns Hopk. Hosp. Rep., 16, 549.

Case, R. B., and Roven, R. B. (1963). Some considerations of coronary flow. Progr. cardiovasc. Dis., 6, 45.

Dimond, E. G., and Benchimol, A. (1963). Correlation of intracardiac pressure and præcordial movement in ischæmic heart disease. Brit. Heart J., 25, 389.

Eldridge, F. L., Hultgren, H. N., Stewart, P., and Proctor, D. (1955). The effect of nitroglycerine upon the cardiovascular system. Stanf. med. Bull., 13, 273.

Essex, H. E., Wegria, R. G. E., Herrick, J. F., and Mann, F. C. (1940). The effect of certain drugs on the coronary blood flow of the trained dog. Amer. Heart J., 19, 554.

Gorlin, R., Brachfeld, N., MacLeod, C., and Bopp, P. (1959). Effect of nitroglycerin on the coronary circulation in patients with coronary artery disease or increased left ventricular work. Circulation, 19, 705.

-, Haynes, F. W., Goodale, W. T., Sawyer, C. G., Dow, J. W., and Dexter, L. (1951). Studies on the circulatory dynamics in mitral stenosis. II. Altered dynamics at rest. Amer. Heart J., 41, 30.

Gregg, D. E. (1950). Coronary Circulation in Health and Disease. Lea and Febiger, Philadelphia.

Honig, C. R., Tenney, S. M., and Gabel, P. V. (1960). The mechanism of cardiovascular action of nitroglycerine. Amer. J. Med., 29, 910.

Johnson, J. B., Fairley, A., and Carter, C. (1959). Effects of sublingual nitroglycerin on pulmonary arterial pressure in patients with left ventricular failure. Ann. intern. med., 50, 34.

Katz, L. N., Lindner, E., Weinstein, W., Abramson, D. I., and Jochim, K. (1938). Effects of various drugs on the coronary circulation of the denervated isolated heart of the dog and cat. Arch. int. Pharmacodyn., 59, 399.

Müller, O., and Rørvik, K. (1958). Hæmodynamic consequences of coronary heart disease; With observations during anginal pain and on the effect of nitroglycerine. Brit. Heart J., 20, 302.

Russek, H. I., Urbach, K. F., and Zohman, B. L. (1955). Paradoxical action of glyceryl trinitrate (nitroglycerin) in coronary patients. J. Amer. med. Ass., 158, 1017.

Sarnoff, S. J., Braunwald, E., Welch, G. H., Jr., Case, R. B., Stainsby, W. N., and Macruz, R. (1958a). Hæmodynamic determinants of oxygen consumption of the heart with special reference to the tension-time index. Amer. J. Physiol., 192, 148.

- Case, R. B., and Macruz, R. (1958b). Observations on the vasodilator properties of urine. I. Comparison of the effect of human urine and nitroglycerin on coronary resistance and myocardial oxygen consumption in the isolated supported heart preparation. Circulat. Res., 6, 522.

Wégria, R., Nickerson, J. L., Case, R. B., and Holland, J. F. (1951). Effect of nitroglycerine on the cardiovascular system of normal persons. Amer. J. Med., 10, 414.

Weiss, S., and Ellis, L. B. (1933). Influence of sodium nitrite on the cardiovascular system and on renal activity in health, in arterial hypertension and in renal disease. Arch. intern. Med., 52, 105.

Weissler, A. M., Gamel, W. G., Grode, H. E., Cohen, S., and Schoenfeld, C. D. (1964). The effect of digitalis on ventricular ejection in normal human subjects. Circulation, 29, 721 .

Williams, J. F., and Glick, G. (1964). Effect of nitroglycerin on ventricular dimensions in intact unanesthetized man. (Abstract). Circulation, 30 Suppl. III, p. 178. 